\title{
Review
}

\section{The Importance of Continuity in Inhaler Device Choice for Asthma and Chronic Obstructive Pulmonary Disease}

\author{
Leif Bjermer \\ Department of Respiratory Medicine and Allergology, Skåne University Hospital, Lund, Sweden
}

For editorial comment see p. 268

\section{Key Words}

Asthma - Chronic obstructive pulmonary disease $\cdot$ Inhaler device - Inhaler switching $\cdot$ Inhalation technique $\cdot$ Patient satisfaction

\begin{abstract}
Inhaled therapies are central to the treatment of asthma and chronic obstructive pulmonary disease. Physicians consider many factors when selecting the most appropriate inhaler device, including device efficacy and the cost to the health care system. This review aims to discuss the factors that are important when considering inhaler devices and the importance of continuity in the choice of inhaler device. A large number of factors can contribute to therapeutic outcomes with inhalation devices. The inhalation technique is critical to treatment success and differs substantially between inhaler devices. Misuse of an inhaler is common, and thorough training of patients and physicians is important to ensure correct utilization. Patient satisfaction is an important consideration because it is significantly correlated with compliance and better outcomes. Financial pressures contribute to decision making: although selecting the less expensive inhaler device might reduce direct treatment costs,
\end{abstract}

it can have a large impact on disease control and the patient's well-being. Switching may be associated with a poor inhalation technique, reduced disease control and quality of life, increased use of other treatments and health care resources, and a greater chance of unsuccessful treatment. Nonconsensual switches can result in patient discontent, reduced confidence in the medication, and uncertainty regarding the degree of disease control. It is recommended that patients with stable disease remain on their current device. If a switch is considered, the patient should be consulted and the physician should take into account the patient's preference, their ability to correctly use the device, and the availability of the preferred drug in the preferred device.

(c) 2014 S. Karger AG, Basel

\section{Introduction}

Inhaled therapies have always been central to the treatment of asthma and chronic obstructive pulmonary disease (COPD) [1], and Global Initiative for Asthma (GINA) guidelines consider the ability to deliver drugs directly to airways a major advantage of inhaled treat-

\section{KARGER}

E-Mail karger@karger.com

www.karger.com/res
C 2014 S. Karger AG, Basel

0025-7931/14/0884-0346\$39.50/0
Prof. Leif Bjermer

Department of Respiratory Medicine and Allergology

Skåne University Hospital

Getingevägen 4, SE-221 85 Lund (Sweden)

E-Mail leif.bjermer@med.lu.se 
ment [2]. The inhalation route provides two distinct advantages: it maximizes the concentrations in the target tissue areas to provide the greatest potential therapeutic effect, and it minimizes systemic concentrations and the risk of adverse events. As such, inhaled corticosteroids (ICS) are considered to be the most effective controller medication available $[2,3]$.

Since the development of the first inhaler in the 1950s [4], a large number of other devices have been developed and at present there are a multitude of drugs and inhaler devices available. While there have been advances in their design and the technology they employ, the perfect inhaler has yet to be produced. The ideal inhalation device would be one that provides:

- complete ease of use to eliminate the potential for incorrect use/technique and effectively deliver the drug even if the patient's technique/coordination is poor

- high levels of drug deposition only in the lung to provide active drug to the required tissues and minimize systemic distribution

- uniform/consistent deposition of the drug, delivering an accurate amount of drug repeatedly and consistently

- dose counter functionality to enable patients to quickly and easily determine the number of doses administered and the quantity of remaining medication

- the option to administer multiple doses in succession without the need to reload the device

- effective delivery of all drug molecule types and sizes

- an inexpensive device cost with low acquisition costs; high procurement costs may be a barrier to health care providers/systems and/or patients.

In addition to these technological and economic factors, the ideal inhaler would be one that is associated with high levels of patient satisfaction, as this factor is thought to improve compliance and treatment outcomes [5].

Physicians treating patients with asthma and COPD consider many factors when selecting the most appropriate treatment and inhaler device, balancing the desire to provide the best treatment with the constraints of an increasingly cost-conscious health care system. The aim of this review is to provide insight into the factors that are important when considering inhaler devices and the importance of continuity in the choice of device for individual patients. The focus is on inhaler devices; comparisons between drugs or combinations of drugs are beyond the scope of this review.

Inhaler Device Continuity in Asthma and COPD

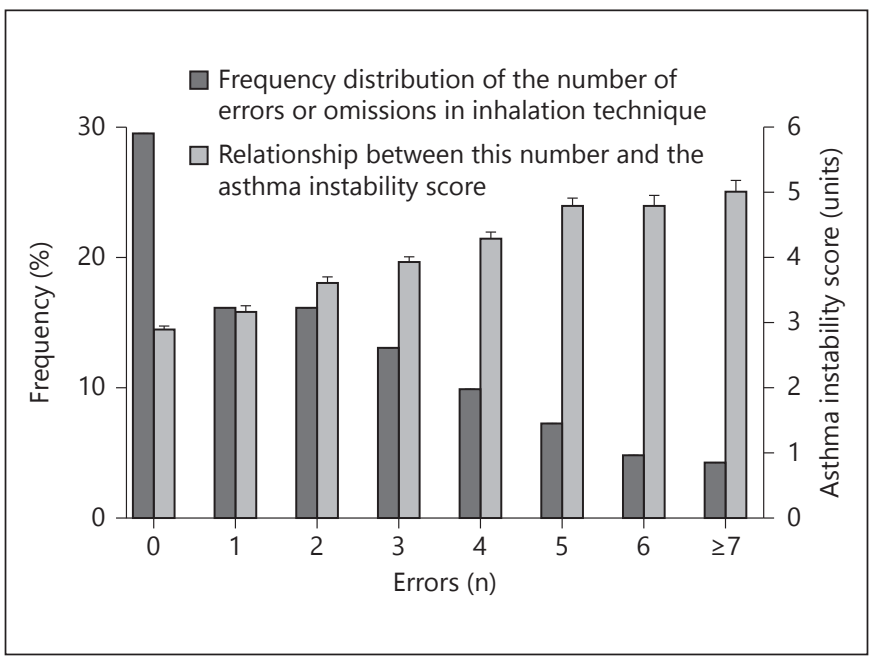

Fig. 1. Correlation between the number of errors in inhalation technique and the asthma instability score [7]. Linear regression analysis: $\mathrm{r}=0.3, \mathrm{p}=0.0001$.

\section{The Challenge of Finding the Right Inhaler Device: The Patients' and Physicians' Interests}

There is a wide range of devices and combinations of treatments available on the market, including branded items and generic versions of existing brands [6]. With such a large number of devices available, it is critical to appreciate that not all devices are the same.

\section{Inhalation Technique}

Inhalation techniques differ substantially between inhaler devices, and the patient's technique can have a large impact on the amount of active drug delivered and therefore on the efficacy and disease control [7].

Incorrect inhaler use has been estimated to be very widespread; one systematic literature review concluded that incorrect inhaler use is very variable depending on the device but can be as high as $94 \%$ [8]. A poor inhalation technique has a clear impact on disease control. In a large physician assessment study, the disease control and inhalation technique of 4,078 patients with asthma were assessed [7]. Patients received ICS and on-demand short-acting $\beta_{2}$-agonists (SABA) via a pressurized metered-dose inhaler (pMDI), and an asthma instability score (a 6-item system including: daytime, nighttime, and exercise symptoms; drug usage; exacerbations, and a global assessment) was used to assess disease control. The inhalation technique was found to be critical (fig. 1): patients who were considered to misuse their pMDI had a 
significantly greater instability than those who were good users.

Patients often misuse their inhalers [7-9], but perhaps this is not surprising given the wide range of techniques required for different inhaler devices $[4,10]$. For example, MDI require good coordination and a slow and deep inhalation, while dry powder inhalers (DPI) require a turbulent flow to transform the metered powder formulation into disaggregated particles. For DPI, the inhalation flow must be maintained from the start of inhalation for a long period of time, so patients are required to breathe as deeply and forcefully as possible [4]. Adding further complexity to this situation is the fact that not all DPI require the same technique and achieving successful delivery with some devices is very technique dependent, i.e. the drug delivery across a variety of inhalation flow rates is relatively stable for some DPI, while for others a high flow rate is associated with a large dose emission [10]. The variability in lung deposition of formoterol among different inhaler devices was illustrated in a study by Weuthen et al. [11]. Using an Andersen Impactor, particle size distributions were determined for two DPI (Foradil ${ }^{\circledR}$ Aerolizer ${ }^{\circledR}$ and Oxis ${ }^{\circledR}$ Turbuhaler ${ }^{\circledR}$ ) across a range of flow rates. While differences in particle size were found between the two inhalers (the Turbuhaler delivered smaller particles than the Aerolizer), the authors consistently observed large variations in drug particle deposition for different flow rates and concluded that the particle size distribution of the inhalers was dependent on the inhalation flow rate (fig. 2). It is therefore critical that patients use the correct technique so that they can receive the specified dose and increase the chances of therapeutic efficacy and disease control.

It is important that patients be provided with adequate education and reeducation to ensure a correct inhalation technique $[3,8,12-14]$. The level of patient education/ time dedicated to inhaler training has been reported to be very low: one quarter of patients do not receive any verbal instruction and almost one-half of patients only receive 1 session of less than $10 \mathrm{~min}[6,8]$. While there is a need for more emphasis and time dedicated to patient training, education initiatives should also target health care professionals - particularly those most responsible for training and education: physicians and pharmacists [14]. Fundamentally, the physician-patient education process is destabilized by the lack of awareness among physicians. It has been estimated that $39-67 \%$ of nurses, doctors, and respiratory therapists are not able to adequately brief patients on correct use [14].

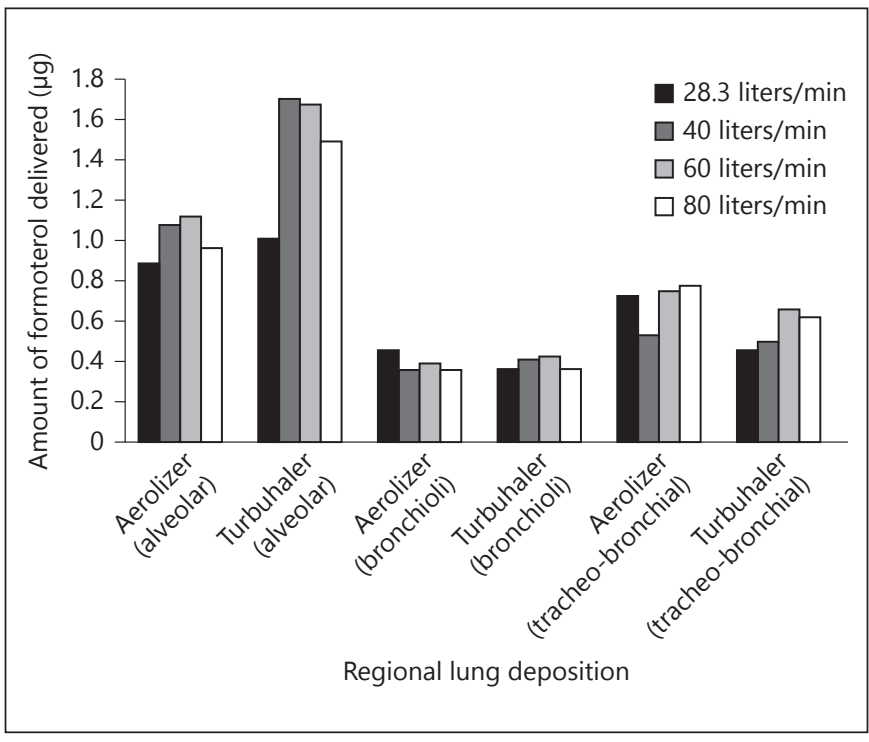

Fig. 2. Variation in lung deposition of formoterol between Turbuhaler and Aerolizer at different inspiratory flow rates [11].

\section{Variation between Devices: Are Devices}

\section{Interchangeable?}

An in vitro examination by Teekamp et al. [15] found that the device characteristics and performance significantly differed between proprietary and generic combination inhalers. Across a range of test pressures, the fine particle fraction and flow rates at the same inhalation effort varied by 2 - to 3 -fold between the Symbicort ${ }^{\circledR}$ Turbuhaler, the Seretide ${ }^{\circledR}$ Diskus ${ }^{\circledR}$, and the generic inhaler Rolenium ${ }^{\circledR}$ Elpenhaler ${ }^{\circledR}$, which could result in large variations in drug distribution to the airways and clinical efficacy.

At first glance, there appears to be conflicting evidence about whether different devices can offer equivalent therapeutic effects when delivering the same drug. A systematic review and meta-analysis of over 100 clinical trials involving patients with stable asthma found that, when devices that deliver SABA were properly used, there was no difference between outcomes with MDI and DPI devices $\left(\right.$ Airmax $^{\mathrm{TM}}$, Autohaler ${ }^{\mathrm{TM}}$, Clickhaler ${ }^{\mathrm{TM}}$, Diskhaler ${ }^{\mathrm{TM}}$, Easyhaler $^{\mathrm{TM}}$, Gentlehaler ${ }^{\mathrm{TM}}$, Rotahaler ${ }^{\mathrm{TM}}$, Spinhaler ${ }^{\mathrm{TM}}$, Spiros $^{\mathrm{TM}}$, Taifun ${ }^{\mathrm{TM}}$, Turbuhaler, and CFC-free or hydrofluoroalkane-propelled pMDI) [16].

In contrast, a real-life retrospective analysis using the IMS Mediplus database found marked differences in disease control in patients with asthma receiving beclomethasone via a Diskhaler or a Rotahaler [17]. The use of SABA was a proxy measure of disease control, and com- 
parisons were made between the year before the first SABA use (index date) and the following year. Significantly less SABA use was observed among patients who used a Diskhaler; the adjusted odds ratio (OR) for not being prescribed a SABA was $1.56(95 \%$ CI $1.01-2.42 ; \mathrm{p}=$ 0.021 ). The apparent contradiction in evidence from realworld and controlled clinical studies may be explained by the structured environment of a controlled clinical trial, which reflects an ideal situation: patients have excellent compliance and are thoroughly briefed on the technique. These circumstances are not routinely achieved in everyday clinical practice.

\section{Patient Adherence}

Even when delivering the same type of drug, the type of device can have an effect on the success of the treatment. In an analysis of inhalation technique and adherence among patients with asthma receiving ICS via an MDI or a DPI, no difference was detected in patient technique scores between the inhalers [18]. However, a significant difference was observed for adherence to ICS therapy - univariate and multivariate analyses indicated that patients were more adherent to DPI inhalers compared to MDI. This study serves to illustrate the importance of the patient in ensuring the success of the treatment and the complexities that arise around adherence. Determining and managing poor adherence is a challenge in primary care because it is not routinely assessed. Patients may misreport nonadherence to avoid disappointing their physician and, in the absence of a specific method to improve adherence, physicians may not actively inquire about it [9].

\section{Patient Satisfaction}

The importance of patient perception and satisfaction was illustrated in a pan-European analysis of real-world data whereby patient satisfaction with their device was correlated with compliance and better outcomes [5]. High levels of patient satisfaction were associated with a greater chance of compliance and of experiencing a significantly better quality of life, fewer exacerbations and hospital/health care visits, and fewer sleep disturbances (all $\mathrm{p} \leq 0.011)$. GINA guidelines identify patient preference, convenience, and ease of use as important factors influencing the efficacy of drug delivery, the patient's adherence to treatment, and disease control [2]. It is therefore critical to ensure that the choice of inhaler device is tailored to the individual $[6,8]$.

Despite the importance of the device, there is very sparse information in asthma and COPD treatment guidelines regarding the impact of specific devices, or switching between devices, on outcomes and treatment adherence [19-21]. While some associations have produced documents to assist physicians - the American College of Chest Physicians and the American College of Asthma, Allergy and Immunology have developed a checklist to aid in physician selection of the inhaler device [22] - the global guidelines have little detailed information on whether substitution may be appropriate in any patient group $[3,12]$.

\section{The Challenge of Finding the Right Inhaler Device: The Health Care Payers' Interests}

Asthma and COPD place a considerable burden on health care budgets; it has been estimated that $1-2 \%$ of the total health care expenditure is attributed to asthma [23], while COPD costs in the USA have been estimated to be more than USD 30 billion per year [24]. Financial pressures play a large role in decision making, and minimizing treatment costs by selecting the less expensive inhaler device might be perceived as a simple means to reduce costs. Indeed, physicians are advised to consider the cheapest available device that a patient can use [16]. However, switching a device solely on the basis of reducing costs could have a large impact on disease control and the patient's well-being.

\section{Implications of Switching Devices}

While it may appear to be a benign decision, changing or switching inhaler devices can have a large effect on disease control. Because different devices require very different techniques for use, switching inhaler devices (in particular nonconsensual switches) may be associated with a poor inhalation technique unless patients are carefully counseled. When not adequately educated, some patients have difficulty operating the device and may even stop using it [25].

In a retrospective, matched, observational study of patients with asthma who either continued the existing therapy with fluticasone propionate/salmeterol $(\mathrm{n}=$ $1,146)$ or were switched to an extra-fine formulation of beclometasone dipropionate/formoterol $(\mathrm{n}=382)$ following either a face-to-face or an electronic review, there was no difference in the number of severe exacerbations reported, with $\sim 80 \%$ of each treatment group reporting no exacerbations and $\sim 6.4 \%$ reporting 2 or more [26]. However, in cases in which a device is switched without 


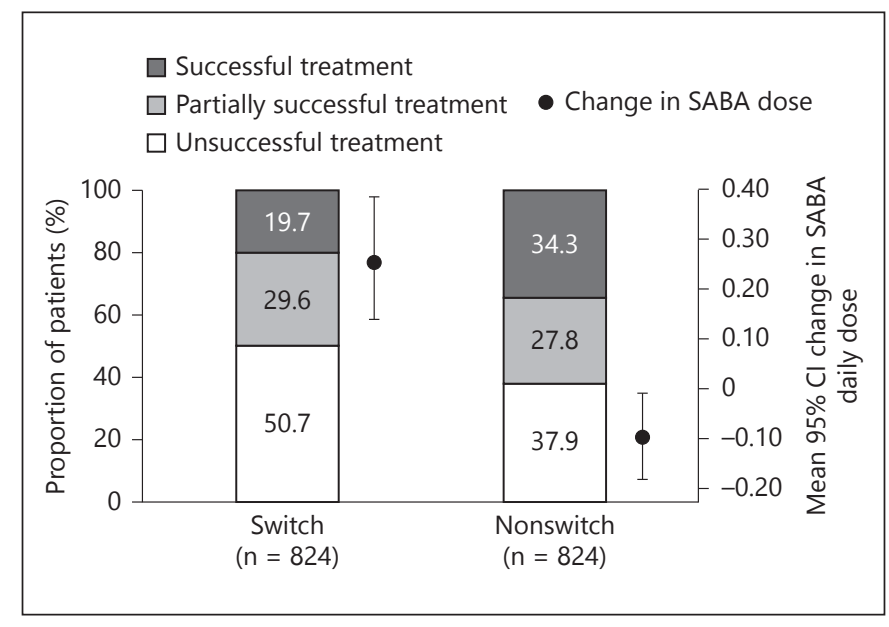

Fig. 3. Effects of switch inhaler devices on the success of treatment and SABA use [27].

discussion with the patient (i.e. nonconsensual switch), this can result in reduced disease control, increased medication use, and a reduction in the confidence the patient has in their physician. Among 824 cohortmatched patients who underwent a nonconsensual switch [the majority (84\%) of the population to a different inhaler type, e.g. DPI to MDI or DPI to a breathactuated inhaler], unsuccessful treatment was more frequent than in nonswitched patients (51 vs. $38 \%$ ), with the adjusted OR of successful treatment being 0.29 (95\% CI $0.19-0.44 ; \mathrm{p}<0.001)$ compared with nonswitched patients (fig. 3) [27]. Furthermore, nonconsensual switches were associated with an increase in SABA use. In a smaller study examining qualitative outcomes among patients with asthma who experienced a nonconsensual switch, patients reported feelings of discontent, less confidence in the asthma medication, and uncertainty regarding the degree of control of their disease [25]. Such discontent can lead to further problems, such as underuse (intentional nonadherence due to problems operating the device) and overuse (due to a lack of confidence in the new medication or the ability to use the device correctly) [25].

Alternative forms of switching, such as transitioning patients from fixed-dose combinations to monotherapy components that are delivered via separate inhaler devices, can also be associated with unsatisfactory outcomes. When a single inhaler device is replaced by multiple inhaler devices in asthma and COPD, a reduced adherence is observed [21, 28, 29]. A retrospective examination of the medical records of more than 11,000 patients was conducted to determine the clinical implications of switching from fixed-dose combinations to mono-component inhalers (a cost-saving decision by the Icelandic government). In this large population of previously well-controlled patients with respiratory disease, the switch from fixed-dose combinations to mono-components was associated with a decrease in adherence and disease control, increased use of oral corticosteroids and SABA, as well as an increase in the number of health care visits [29]. These outcomes were consistent with other observations of reduced adherence with the use of multiple inhalers. In a real-life retrospective analysis of 23,494 patients with COPD, persistence and adherence to treatment were greater in patients using a single inhaler compared to multiple inhalers [28]. Using US claims data, two populations of patients with COPD were matched based on single- or multi-inhaler regimens as well as demographics and baseline characteristics; persistence (rate of discontinuation) and adherence (proportion of days covered) were compared. Multiple inhaler use was associated with significantly higher rates of discontinuation (over the 12 -month study period, HR $1.40, \mathrm{p}<0.001$ ) and significantly lower rates of 12 -month adherence (proportion of days covered: 0.51 vs. 0.55 for a single inhaler, $\mathrm{p}<$ 0.0001).

Conversely, simplification of treatment strategies and minimization of inhaler options have been shown to improve adherence and have positive effects on disease control in some patients. In an open-label study among patients with low adherence and poorly controlled asthma, the use of a single inhaler containing a fixed-dose ICS/ LABA for maintenance and reliever therapy was associated with increased medication use and better outcomes in patients with asthma compared to those using an ICS/ LABA inhaler plus a SABA inhaler [30].

It is important that, when a switch of inhaler device is contemplated, the indirect effects of switching - such as reduced disease control and quality of life, increased use of other treatments, and health care resources - be considered. Compared to savings from direct costs alone, investing in training and education to ensure that there is a high level of adherence to the treatment may lead to greater savings through reduced demands on health care systems and consultations [31]. Furthermore, when switching to another treatment the implications for disease control must be considered because the cost of emergency treatment is acknowledged as being greater than that of planned treatment [3]. Before initiating a switch of treatment, physicians should carefully consider the patient's circumstances: the 2011 European Respiratory Society 


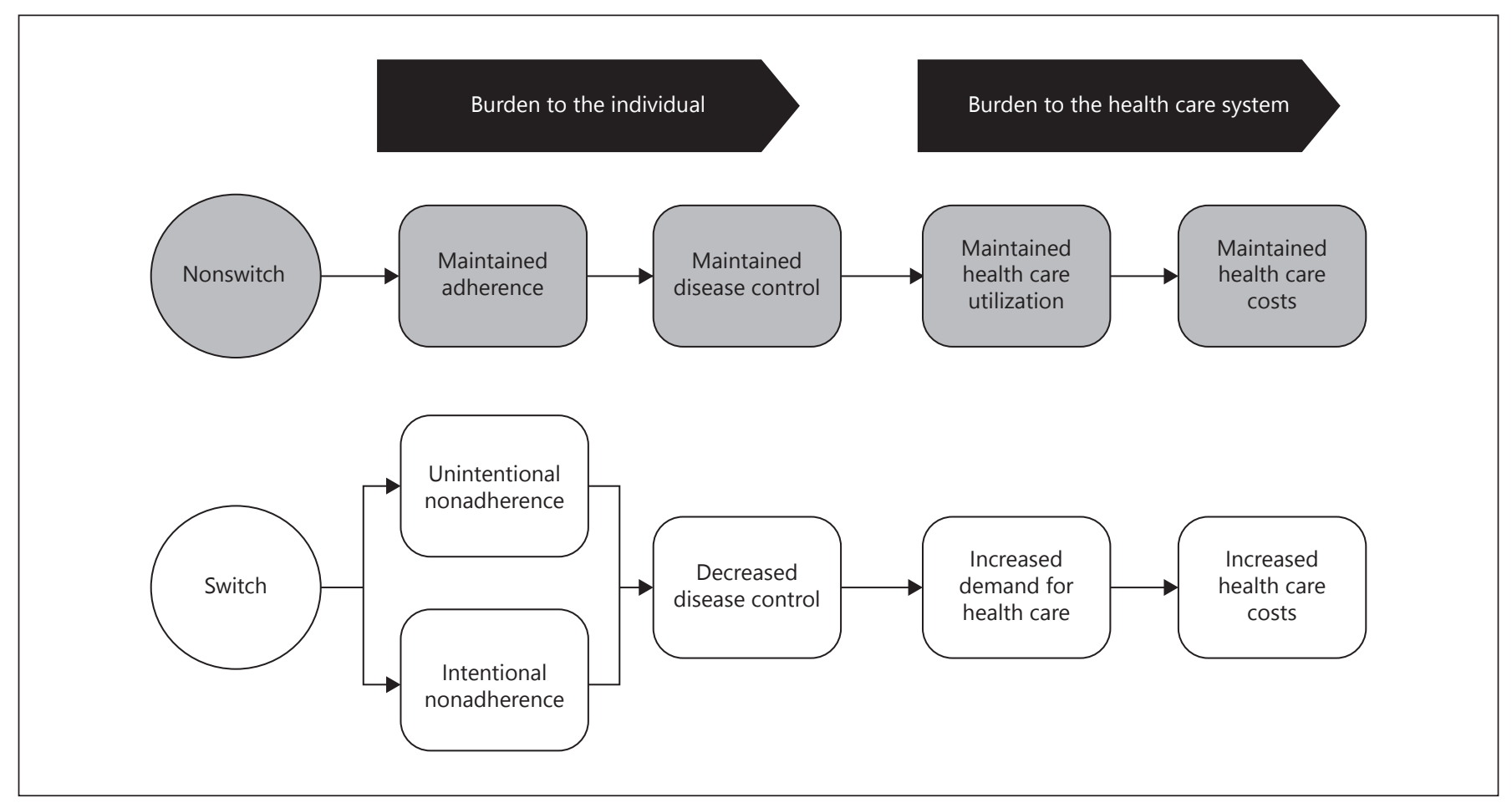

Fig. 4. Implications for switching inhaler devices from the perspective of the patient and the health care system [31].

(ERS) and the International Society for Aerosols in Medicine (ISAM) Task Force report recommend that patients remain on their current inhaler if their disease is stable, rather than switching to another device [32].

\section{Conclusions}

In the management of respiratory diseases with inhalation devices, there are a large number of factors that affect therapeutic outcomes - different devices require different techniques, the delivery of drugs can vary between similarly designed devices, training of patients is often lacking, the patient's technique is often incorrect, and the patient's adherence appears to depend on which device they use. To maintain disease control in both asthma and COPD, device continuity is important. Indeed, it is recommended by the ERS and the ISAM that patients with stable disease remain on their current device rather than switching [32].

When considering a switch of inhaler device, it is important to take into account all of the potential implications (fig. 4) and prepare the patient for the switch. Prescribers should not only consider the drug/device acqui- sition costs but also the costs associated with additional health care resources that the patient may need if the switch leads to decreased disease control. The patient should be consulted and the physician should also take into account the patient's preference, their ability to correctly use the device, and the availability of the preferred drug in the preferred device. Furthermore, the regimen should be simplified when possible (i.e. inhalers should not be mixed) and the patient should be given adequate training and then carefully monitored.

\section{Acknowledgements}

Medical writing assistance for this review was provided by Matt Weitz of inScience Communications, Springer Healthcare. This assistance was funded by AstraZeneca.

\section{Financial Disclosure and Conflicts of Interest}

Leif Bjermer has, during the last 3 years, received honoraria for attending advisory boards or giving lectures for the following companies: Almirall, AstraZeneca, Airsonette, Andre Pharma-Chiesi, Boehringer, GlaxoSmithKline, Meda, Merck, Mundipharma, Nigaard Pharma, Novartis, Pfizer, Takeda/Nycomed, and Teva. 


\section{References}

-1 Palander A, Mattila T, Karhu M, Muttonen E: In vitro comparison of three salbutamol-containing multidose dry powder inhalers. Clin Drug Investig 2000;20:25-33.

-2 Bateman ED, Hurd SS, Barnes PJ, Bousquet J, Drazen JM, FitzGerald M, Gibson P, Ohta K, O’Byrne P, Pedersen SE, Pizzichini E, Sullivan SD, Wenzel SE, Zar HJ: Global strategy for asthma management and prevention: GINA executive summary. European Respir J 2008; 31:143-178.

3 Global Initiative for Asthma: Global strategy for asthma management and prevention. 2012. http://www.ginasthma.org/documents/5/ documents_variants/37.

$\checkmark 4$ Chrystyn H, Price D: What you need to know about inhalers and how to use them. Prescriber 2009;20:47-52.

$\checkmark 5$ Small M, Anderson P, Vickers A, Kay S, Fermer S: Importance of inhaler-device satisfaction in asthma treatment: real-world observations of physician-observed compliance and clinical/patient-reported outcomes. Adv Ther 2011;28:202-212.

6 Capstick TG, Clifton IJ: Inhaler technique and training in people with chronic obstructive pulmonary disease and asthma. Expert Rev Respir Med 2012;6:91-101, quiz 102-103.

7 Giraud V, Roche N: Misuse of corticosteroid metered-dose inhaler is associated with decreased asthma stability. Eur Respir J 2002;19: 246-251.

-8 Lavorini F, Magnan A, Dubus JC, Voshaar T, Corbetta L, Broeders M, Dekhuijzen R, Sanchis J, Viejo JL, Barnes P, Corrigan C, Levy M, Crompton GK: Effect of incorrect use of dry powder inhalers on management of patients with asthma and COPD. Respir Med 2008; 102:593-604.

$>9$ Haughney J, Price D, Kaplan A, Chrystyn H, Horne R, May N, Moffat M, Versnel J, Shanahan ER, Hillyer EV, Tunsater A, Bjermer L: Achieving asthma control in practice: understanding the reasons for poor control. Respir Med 2008;102:1681-1693.

$>10$ Abdelrahim ME: Emitted dose and lung deposition of inhaled terbutaline from Turbuhaler at different conditions. Respir Med 2010;104:682-689.

-11 Weuthen T, Roeder S, Brand P, Mullinger B, Scheuch G: In vitro testing of two formoterol dry powder inhalers at different flow rates. J Aerosol Med 2002;15:297-303.

12 Global Initiative for Obstructive Lung Disease: Global strategy for diagnosis, management, and prevention of COPD. 2011. http://www. goldcopd.org/guidelines-gold-summary2011.html.
13 Takemura M, Kobayashi M, Kimura K, Mitsui $\mathrm{K}$, Masui H, Koyama M, Itotani R, Ishitoko M, Suzuki S, Aihara K, Matsumoto M, Oguma T, Ueda T, Kagioka H, Fukui M: Repeated instruction on inhalation technique improves adherence to the therapeutic regimen in asthma. J Asthma 2010;47:202-208.

14 Fink JB, Rubin BK: Problems with inhaler use: a call for improved clinician and patient education. Respir Care 2005;50:1360-1374, discussion 1374-1375.

15 Teekamp N, Hagedoorn P, Huijbers BG, Gjaltema D, Frijlink HW, De Boer AH: Comparison of the in vitro performance of originator and generic drug-combination dry powder inhalers. Eur Respir Soc Annu Congress, Barcelona, 2013, p 856019.

16 Ram FS: Clinical efficacy of inhaler devices containing beta(2)-agonist bronchodilators in the treatment of asthma: Cochrane systematic review and meta-analysis of more than 100 randomized, controlled trials. Am J Respir Med 2003;2:349-365.

17 Thomas M, Williams AE: Are outcomes the same with all dry powder inhalers? Int J Clin Pract Suppl 2005;149:33-35.

18 Roy A, Battle K, Lurslurchachai L, Halm EA, Wisnivesky JP: Inhaler device, administration technique, and adherence to inhaled corticosteroids in patients with asthma. Prim Care Respir J 2011;20:148-154.

19 Dekhuijzen PNR, Picado C, Lavorini F, Ninane V, Haughney J: Inhaler choice in asthma and COPD: a poorly addressed issue in guidelines - Breathing New Life. 6th IPCRG World Conf. Edinburgh, 2012.

20 Papi A, Haughney J, Virchow JC, Roche N, Palkonen S, Price D: Inhaler devices for asthma: a call for action in a neglected field. Eur Respir J 2011;37:982-985.

21 Makela MJ, Backer V, Hedegaard M, Larsson $\mathrm{K}$ : Adherence to inhaled therapies, health outcomes and costs in patients with asthma and COPD. Respir Med 2013;107:1481-1490.

22 Dolovich MB, Ahrens RC, Hess DR, Anderson P, Dhand R, Rau JL, Smaldone GC, Guyatt G: Device selection and outcomes of aerosol therapy: evidence-based guidelines American College of Chest Physicians/ American College of Asthma, Allergy, and Immunology. Chest 2005;127:335-371.
23 Haahtela T: The disease management approach to controlling asthma. Respir Med 2002;96(suppl A):S1-S8.

24 Cote C: Pharmacoeconomics and the burden of chronic obstructive pulmonary disease. Clin Pulm Med 2005;12:S19-S21.

25 Doyle S, Lloyd A, Williams A, Chrystyn H, Moffat M, Thomas M, Price D: What happens to patients who have their asthma device switched without their consent? Prim Care Respir J 2010;19:131-139.

26 Price D, Small I, Haughney J, Ryan D, Gruffydd-Jones K, Lavorini F, Harris T, Burden A, Brockman J, King C, Papi A: Clinical and cost effectiveness of switching asthma patients from fluticasone-salmeterol to extra-fine particle beclometasone-formoterol: a retrospective matched observational study of realworld patients. Prim Care Respir J 2013;22: 439-448.

27 Thomas M, Price D, Chrystyn H, Lloyd A, Williams AE, von Ziegenweidt J: Inhaled corticosteroids for asthma: impact of practice level device switching on asthma control. BMC Pulm Med 2009;9:1.

28 Yu AP, Guerin A, Ponce de Leon D, Ramakrishnan K, Wu EQ, Mocarski M, Blum S, Setyawan J: Therapy persistence and adherence in patients with chronic obstructive pulmonary disease: multiple versus single long-acting maintenance inhalers. J Med Econ 2011;14: 486-496.

29 Björnsdóttir US, Jonsson JS, Jonsson M, Sigurðardóttir ST, Stratelis G, Telg G, Thuresson M, Gizurarson S: Impact of reimbursement changes for fixed ICS/LABA combination treatment in Iceland (abstract). The Eur Respir J 2012;40:P1005.

30 Sovani MP, Whale CI, Oborne J, Cooper S, Mortimer K, Ekstrom T, Tattersfield AE, Harrison TW: Poor adherence with inhaled corticosteroids for asthma: can using a single inhaler containing budesonide and formoterol help? Br J Gen Pract 2008;58:37-43.

31 Bjornsdottir US, Gizurarson S, Sabale U: Potential negative consequences of non-consented switch of inhaled medications and devices in asthma patients. Int J Clin Pract 2013; 67:907-910.

32 Laube BL, Janssens HM, de Jongh FH, Devadason SG, Dhand R, Diot P, Everard ML, Horvath I, Navalesi P, Voshaar T, Chrystyn $\mathrm{H}$ : What the pulmonary specialist should know about the new inhalation therapies. Eur Respir J 2011;37:1308-1331. 